\title{
CREATININE CLEARNCE RATE (CCR) IN DIGNOSING DIFFERENT STAGES OF CHRONIC KIDNEY DISEASE (CKD) - AN UPDATE AND REVIEW
}

\author{
M.M JAHANGIR ALAM ${ }^{1}$, FAZLE RABBI CHOWDHURY ${ }^{2}$, FAIZUL ISLAM CHOWDHURY ${ }^{3}$, ANUP \\ KUMAR SAHA $^{4}$, AKM AMINUL HOQUE $^{5}$, MD. MUJIBUR RAHMAN ${ }^{6}$
}

\section{Introduction}

Chronic Kidney Disease refers to an irreversible deterioration in renal function, which classically develops over a period of months to years. Serum creatinine concentration is a reliable guide to renal function, as it is produced from muscle at a constant rate and almost completely filtered in the glomerulus. ${ }^{1}$ But, serum creatinine does not rise above the normal range until there is a reduction of $50 \%-60 \%$ in glomerular filtration rate (GFR). So, a normal serum creatinine is not synonymous with a normal glomerular filtration rate. Measurement of the GFR is necessary to define the exact level of renal function. ${ }^{2}$

In clinical practice, the clearance rate of endogenous creatinine, the creatinine clearance rate (CCR), is the usual means of estimating GFR ${ }^{3}$. Creatinine Clearance Rate is relatively simple to measure can be estimated by assessing urine and serum creatinine concentration. Typically 24 hours urine is used for the study. Since, urine collection may be difficult, creatinine clearance rate can be estimated from the formula of Cockcroft and Gault, which incorporate age, sex and weight to estimate creatinine clearance rate from plasma creatinine level without any urinary measurement. ${ }^{5}$

It can be used to estimate the glomerular filtration rate in a patient with chronic kidney disease (CKD). It can be measured once a year in person with stable renal function to detect any deterioration over time. ${ }^{6}$ Some times, in early stages, chronic kidney disease cannot be detected confidently by the measurement of serum creatinine concentration alone. In these situations, measurement of creatinine clearance rate would be helpful.

\section{ANATOMY OF THE KIDNEYS ${ }^{7}$}

Adult kidneys are $11-14 \mathrm{~cm}$ (three lumber vertebral bodies) in length, and are located retroperitonealy on either side of the aorta and inferior vena cava. Each kidney contains 1 million functional units, or 'nephrons'. These consists of glomerulus's (where filtration of plasma occurs), proximal convoluted tubule, loop of Henle and distal convoluted tubule (where selective reabsorption of fluid and solutes from the filtrate occurs), and the collecting duct. The collecting ducts of multiple nephrons drain into the renal pelvis and ureter. There is a rich blood supply ( $20 \%$ - $25 \%$ of cardiac output). Intralobular branches of the renal artery give rise to the glomerular afferent arterioles which supply the capillaries within the glomerulus. The efferent arteriole, leading from the glomerulus, supplies the distal nephron and medulla in a 'portal' circulation.

\section{Glomeruli $^{7}$}

The glomerulus contains three main cell types: endothelial cells lining the glomerular capillaries, epithelial cells and mesangial cells. Mesangial cells lie in the central region of the glomerulus. They have similarities to vascular smooth muscle cells. (eg. contractility), but also some macrophage-like properties. Filtration occurs across the glomerular basement membrane (GBM), produced by fusion of the basement membranes of epithelial \& endothelial cells. The glomerular capillary endothelial cells contain pores (fenestrae) which allow access of circulating molecules to the underlying GBM. On the outside of the GBM, glomerular epithelial cells (Podocytes) put out multiple long foot processes which interdigitate with those of adjacent epithelial cells. As well as maintaining the filtration barrier, podocytes are involved in the regulation of filtration and of GBM turnover.

The filtration barrier at the glomerulus is normally almost absolute to proteins the size of albumin $(67 \mathrm{KDa})$ or larger, while proteins of $20 \mathrm{KDa}$ or smaller

1. MD-Final Part student, Dhaka Medical College

2. Post Graduate Trainee, Department of Medicine, Dhaka Medical College

3. Assoicate Professor of Medicine, Dhaka Medical College

4. Consultant (Medicine), Central Police Hospital, Dhaka

5. Associate Professor of Medicine, Mymensingh Medical College, Mymensingh

6. Professor of Medicine, Begum Khaleda Zia Medical College, Dhaka 
are able to filter freely. Between these sizes the ability of individual molecules to cross the GBM is influenced by their shape and charge. Anionic proteins are relatively less freely filtered than cationic proteins. Little lipid is filtered.

Filtration pressure at the GBM is controlled by afferent and efferent arteriolar tone. Auto regulation maintains a constant glomerular filtration rate (GFR) by altering this arteriolar tone over a wide range of systemic blood pressure and renal perfusion pressure. In response to a reduction in perfusion pressure, angiotensin-II mediates constriction of the efferent arteriole, which restores filtration pressure.

\section{Functions of the kidneys: ${ }^{7}$}

In health, the volume and composition of the body fluids are tightly regulated and the kidneys are largely responsible. This achieved by making large volume of an ultra-filtrate of plasma $(120 \mathrm{ml} / \mathrm{min}$, 170 liters/ day) at the glomerulus, and selectively reabsorbing components of this ultra-filtrate at points along the nephron. The rates of filtration are under the control of many hormonal and haemodynamic signals.

Some metabolites either are not reabsorbed from the filtrate, or are actively secreted into it. The kidney is primarily responsible for excretion of many metabolic breakdown products (including ammonia, urea and creatinine from protein, and uric acid from nucleinc acids), drugs and toxins. In addition, the kidney has a number of hormonal functions. Three of these are particularly important: release of erythropoietin in response to hypoxia, vitamin $\mathrm{D}$ metabolism, secretion of renin.

Before going to the main discussion we would like to highlight some points about Chronic Kidney Disease.

\section{Chronic kidney disease}

Definition and stages:

National kidney foundation defines chronic kidney disease (CKD) as either kidney damage or a decreased glomerular filtration rate of $<60 \mathrm{ml} / \mathrm{min}$ / $1.73 \mathrm{~m}^{2}$ for 3 or more months. Whatever the underlying aetiology, it is that the destruction of renal tissue or a progressive decline in GFR within determines the progression of CKD.

Prior to February 2002, no uniform Classification of the stages of CKD existed. At that time, K/DOQI published a classification of the stages of CKD as follows:-

Stage 01 : Kidney damage with normal (GFR $\geq 90$ $\mathrm{ml} / \mathrm{min}$.)

or high GFR.

Stage 02 : Kidney damage with $(\mathrm{GFR}=60-89 \mathrm{ml} /$ $\min$.)

slightly low GFR.

Stage: 03 : Kidney damage with moderately low GFR (GFR = 30-59 $\mathrm{ml} / \mathrm{min})$.

Stage 04 : Severely low GFR (GFR $=15-29 \mathrm{ml} / \mathrm{min}$.)

Stage 05 : Kidney failure (GFR $<15 \mathrm{ml} / \mathrm{min}$,) or on dialysis.

The K/DOQI definition and the classification of CKD allow better communication and intervention at the different stages.

\section{Frequency of CKD :-}

Internationally - the incidence rates of end stage renal disease (ESRD) have increased steadily since 1989. The United States has the highest incidence rate of ESRD followed by Japan. Which has the highest prevalence per million population, with the United States taking second place. ${ }^{8}$

In the United States: The US Renal Data System has shown a dramatic increase in patients with CKD who require chronic dialysis or transplantation. In 1999 there were 340,000 such patients, but, 2010, this number is projected to reach $651,000 .{ }^{9} \mathrm{CKD}$, particularly at the stage requiring renal replacement therapy, is already a major burden to health care resources, and this will only worsen in time.

Because of the non uniform definition of chronic kidney disease prior to February 2002, among other factors, most patients with earlier CKD stages have not been recognized or adequately treated. The third National Health and Examination Survey estimated that prevalence of CKD in adults in the United States was $11 \%$ (19.2million) of them-
$3.3 \%-$
5.9 million had stage $1 \mathrm{CKD}$
$3.0 \%$ - $\quad 5.3$ million had stage $2 \mathrm{CKD}$
$4.3 \%$ - $\quad 7.6$ million had stage $3 \mathrm{CKD}$
$0.2 \%$ - $\quad 400,000$ had stage $4 \mathrm{CKD}$
$0.2 \%$ - $\quad 300,000$ had stage $5 \mathrm{CKD}$ 


\section{Causes of chronic kidney disease ${ }^{10}$}

A. Vascular disease :-

i. Hypertensive nephrosclerosis.

ii. Renal artery stenosis

iii. ANCA positive vasculitis etc.

B. Primary glomerular disease :-

i. Membranous nephropathy.

ii. Ig A nephropathy.

iii. Focal \& segmental glomerulosclerosis(FSGS) etc.

C. Secondary glomerular disease :-

i. Diabetes mellitus.

ii. Systemic lupus erythematosus.

iii. Rheumatoid arthritis.

iv. Mixed connective tissue disease etc.

D. Tubulo interstitial disease :-

i. Drugs-eg, Sulfa, Allopurinol etc.

ii. Infection -eg, viral, bacterial, Parasitic etc.

A. Urinary tract obstruction :-

i. Urolithiasis.

ii. Benign prostatic hypertrophy etc.

Pathophysiology of CKD :-

Each nephron contributes to the total GFR. Regardless of the aetiology of renal injury, with progressive destruction of nephrons the kidney has an innate ability to maintain GFR by hyperfiltration and compensatory hypertrophy of the remaining healthy nephrons. This nephron adaptabiliy allows for continued normal clearance of plasma solutes such that, substances such as urea \& creatinine start to show significant increaser in plasma level only after total GFR has decreased to $50 \%$, when the renal reserve has been exhausted. The plasma creatinine value will be double with a $50 \%$ reduction of GFR. A rise in plasma creatinine from a base line value of $0.6 \mathrm{mg} / \mathrm{dl}$ to $1.2 \mathrm{mg} / \mathrm{dl}$ in a patient, although still within the reference range, actually represents a loss of $50 \%$ of functional nephron mass.

Since, uraemic syndrome resembles asystemic intoxication, the search for a putative uraemic toxin has been the subject of intensive investigation. As yet, however, no single compound has been found to produce the clinical picture of uraemia. Therefore, it is more likely that multiple factors confribute to the pathogenesis of this syndrome. e.g.

\section{A. Retained metabolic Product:-}

Many chemical compounds have been suspected to be responsible for the uremia syndrome, e.g.
Acetone, amino acid, amines, creatinine, â2 microglobulin.

\section{B. Over production of counter regulatory hormones:-}

Overproduction of parathyroid hormone (PTH) in response to hypocalcaemia and natriuretic hormone in responde to volume overload could contribute to many aspects of the uraemic state.

\section{Under Production of renal hormones:-}

Decreased erythropoietin production causes anemia. Decreased $1 \alpha$-hydroxylation of vit D3 contributes to bone disease. Clearly, these and other such deficiencies could play a role in the uraemic state.

Diagnosis: ${ }^{14}$

The first step is to determine whether the renal failure is acute, chronic or acute superimposed on chromic. Progression to CKD is common when the serum creatinine concentration is $>1.5$ to $2 \mathrm{mg} / \mathrm{dl}$. This may occur even if the underlying disorder is not active. Obtaining a precise diagnosis becomes increasingly difficult as the patient approaches end stage renal disease. The definitive diagnostic tool is renal biopsy, but it is not recommended when ultrasonography indicates that the kidneys are small and fibrotic.

Investigations done in chronic Kidney disease: The following investigations are usually done in case of CKD like Urine analysis,Serum creatinine ,BUN, Creatinine clearance,Serum potassium,Arterial blood gas and blood chemistry,Renal or abdominal X-ray, Abdominal CT scan, Abdominal MRI, Abdominal Ultrasound,Test for Urinary cast, Renal scan, Parathyroid hormone level,.Serum Magnesium, Erythropoietin level.

\section{Creatinine Clearance Rate:}

The creatinine clearance rate compares the level of creatinine in urine with with in the blood, usually based on measurement of a 24 hour urine sample and blood sample drawn at the end of the 24 hours period. It is measured as $\mathrm{ml} / \mathrm{min}$.

Because, creatinine is found in stable plasma concentration, is freely filtered and not reabsorbed, and is minimally secreted by the kidneys, creatinine clearance rate is used to estimate the glomerular filtration rate (GFR) - the standard by which kidney function is assessed. 
How the test is performed:

i. A 24 hour urine sample is generally required. Occasionally 6 or 12 hours urine collection can be done alternatively.

ii. Blood sample is drawn from vein at the end of 24-hour period. Both urine \& blood sample will be tested in laboratory to measure creatinine concentration.

Than Creatinine Clearance Rate is calculated as follows:-

\section{Limitations:}

a) Some patients can have fluctuating renal function sufficient to interfere with the evaluation.

b) 24 hour urine collection may be difficult.

c) Shorter period of time can be used but misleading information can be derived.

Alternate Methods of Measuring Creatinine Clearance Rate:

1. The Cock croft \& Gault (C\&G) equation is reasonably accurate at normal to moderately impaired renal function. This equation incorporate age, sex and weight to estimate creatinine clearance rate from plasma creatinine levels without any urinary measurements.

(140-1ge) $\mathrm{x}$ lean body weight in $(\mathrm{kg}) \mathrm{x}$ 1.22 males No. 04 Females)

$\mathrm{CCR}(\mathrm{ml} / \mathrm{min})$

\section{S. Creatinine $(\mu \mathrm{mol} / \mathrm{L})$}

2. Complex equations have been development which are better at poorer levels of renal function. The modification of Diet in Renal Disease (MDRD) study equation, this equation is more accurate than Cock croft \& Gault equation.

\section{MDRD equation is : ${ }^{23}$}

Creatinine clearance rate (in $\mathrm{ml} / \mathrm{min}$ )

$=186$ (creatinine in $\mu \mathrm{mol} / \mathrm{L} / 88.4$ ) 1.154 (Age in yrs)

0.203 (0.742 if female) 1.210 if black).

\section{Correction:}

Total body mass is roughly proportional to body surface area (BSA). Correction for BSA is necessary if the BSA of the patient differ markedly from the average.
Standardized Creatinine Clearance Rate $=$ Calculated Creatinine Clearance X (1.73/BSA in square meter)

Where, 1.73 is the BSA of average size person in square meter. ${ }^{24}$

\section{Factors affecting creatinine clearance:}

1. Sex - It is normally less in women than men.

2. Age- It is lower in children until the age of 2 years

It usually decreases in adults with age, starting at the age of 30 years.

3. Muscle mass -This is the reason for decrease seen in elderly. It can also be important in patients with cachexia.

4. Pregnancy

5. Hyperglycemia - Due to osmotic diuresis and body fluid redistribution.

6. Patients with morbid obesity or marked ascites; They execrete less creatinine per $\mathrm{kg}$ than expected. It need to be corrected to lean body weight if they are marked.

7. Protein urea: This results in increased creatinine clearance.

8. Time of day - It is highest in afternoon

9. Medication (Decrease tubular secretion of creatinine, so decrease creatinine clearance e. g. Cimetidine. Procainamide, Antibiotics. Quinidine etc.

\section{Uses of creatinine clearance Rate:}

Measurement of creatinine clearance rate can be used to estimate the glomerular filtration rate (GER) in a patients with Chronic Kidney Disease, Testing should be done periodically to monitor renal finction and to detect any deterioration over time.

Creatinine clearance can be measured once a year in a person with stable renal function.

It can be measured more often if the patient has:

i) GFR $<60 \mathrm{ml} / \mathrm{min} / 1.73 \mathrm{~m}^{2}$

ii) A decline in GFR $>4 \mathrm{ml} / \mathrm{min} / 1.73 \mathrm{~m} 2$ per year.

iii) Deterioration / progression in the disease causing the chronic renal dysfunction.

iv) Exposure to risk factors for an acute decline in GFR e.g. urinary tract obstruction, volume depletion, exposure to nephrotoxie drugs.

v) Ongoing therapy to slow progression in the decline of renal function. ${ }^{6}$ 
Normal Creatinine Clearance Rate

A. For Men :

Average $-120 / \mathrm{min} / 1.73 \mathrm{~m}^{2}( \pm 25)$

Range - $97-137 \mathrm{ml} / \mathrm{min} / 1.73 \mathrm{~m}^{2}$

B. For women:

Average $-95 \mathrm{ml} / \mathrm{min} / 1.73 \mathrm{~m}^{2}( \pm 20)$

Range $-88128 \mathrm{ml} / \mathrm{min} / 1.73 \mathrm{~m}^{2}$

Serum Creatinine Concentrations and creatinine clearance rates: ${ }^{25}$

\begin{tabular}{lcc}
\hline $\begin{array}{l}\text { Renal } \\
\text { Function }\end{array}$ & $\begin{array}{c}\text { Serum creatinine } \\
\text { concentration }\end{array}$ & $\begin{array}{c}\text { creatinine clearance } \\
(\mathrm{mg} / \mathrm{dl}) \text { rate }(\mathrm{ml} / \mathrm{min} \\
\left./ 1.73 \mathrm{~m}^{2}\right)\end{array}$ \\
\hline Normal & $<1.3$ & $130 \pm 15$ \\
Mild renal failure & $1.3-1.9$ & $56-100$ \\
Moderate renal failure & $2-4$ & 35.55 \\
Severe renal failure & $>4$ & $<35$ \\
\hline
\end{tabular}

\section{Conclusion:}

Prior to February 2002, before the development of the uniform classification of the stages of chronic kidney disease, most patients with earlier CKD stages have not been recognized or adequately treated. At that time, National Kidney Foundation Kidney Disease Outcome \& Quality Initiative (K/ DOQI) published a classification of the stages of CKD, which is based on glomerular filtration rate (GFR). Creatinine clearance rate (CCR) is the estimate of GFR. So, measurement of creatinine clearance rate, now can detect many earlier stages of CKD patients.

Patients with chronic kidney disease stage 3 or lower stage (GFR $>30 \mathrm{ml} / \mathrm{min}$ ) generally are asymptomatic and do not experience clinically evident disturbances in water or electrolyte balance, or endocrine/ metabolic derangements. Generally, these disturbances clinically manifest with CKD stages 4 \& $5(\mathrm{GFR}<30 \mathrm{ml} / \mathrm{min})$.

Moreover, after 30 years of age, progressive physiological glomerulosclerosis occurs, with GFR and creatinine clearance falling linearly at a rate of appropriately $8 \mathrm{ml} / \mathrm{min} / 1.73 \mathrm{~m}^{2} /$ year from a maximal GFR $140 \mathrm{ml} / \mathrm{min} / 1.73 \mathrm{~m}^{2}$. Aging also results in concomitant progressive physiological decrease in muscle mass such that daily urinary creatinine concentration also decreases. This combination of factors result in constant serum creatinine values over time in a given individual; despite a decrease in creatinine clearance (and GFR). Therefore, a serum creatinine value of $0.8 \mathrm{mg} / \mathrm{dl}$ in a $70 \mathrm{~kg}, 25$ years old man versus one who is in 80 years old represents a creatinine clearance of $140 \mathrm{ml} / \mathrm{min}$ and $73 \mathrm{ml} / \mathrm{min}$ respectively. What can appear as only mild renal impairment in an $80 \mathrm{yr}$ old $70 \mathrm{~kg}$ man with a pathologically elevated serum creatinine of $2.0 \mathrm{mg} /$ $\mathrm{dl}$; actually represents severe renal impairment when the creatinine clearance is calculated to be $29 \mathrm{ml} /$ min.

Therefore, a creatinine clearance must be calculated simply by Cockcoroft \& Gault formula in elderly people so that, patient in different stages of chronic kidney disease can be detected more confidently than that would be suggested by the serum creatinine alone. ${ }^{12}$

\section{References:}

1. Turner AN. Savi8l J. Stewart LH. Cumming A., Kidney \& Genitourinary Disease, In : Haslet C. Chilvers ER. Boon NA. Colledge NR. Hunter JAA. Davidson's Principles and Practice of Medicine, $19^{\text {th }}$ ed, Churchill Livingstone UK, 2002, P-581-600.

2. Baker LRI, Renal disease, In : Kumar P, Clark M, Clinical Medicine, $5^{\text {th }}$ ed., WB Saunders, UK, 2002, P-590-91.

3. Watrik S. Morrison G. Kidney, In : Tierney LM, Me Phee SJ, Papadakis MA. Current Medical Diagnosis \& Treatment, $43^{\text {rd }}$ ed. Me Graw Hill, 2004, P-865.

4. Pincus MR, Methods Preuss HG, Clinical Diagnosis \& Management by laboratory Methods, $19^{\text {th }}$ ed. WB Saunders, 1996.

5. Cockcroft DW, Gault MH. Prediction of creatinine clearance from serum creatinine, Nephron 1976; 16:31-41.

6. National Kidney Foundation, Kidney Disease Outcomes Quality Initiative (K/DOQI), Clinical guidelines for Chronic Kidney Disease, Evaluation, Classification and Stratification. Am J Kidney Disease, USA, 2002; 39 (S2): S1-S266 (P-S 170-71).

7. Goddard J, Turner AN, Cumming AD, Stewart P; Kidney and Urinary Tract Disease, In : Boon NA, Colledge NR, Walker BR, Hunter JAA, Davidson's Principles and Practice of Medicine, $20^{\text {th }}$ ed. Churcill Livingstone, UK, 2006 P458-60.

8. United States Renal Data System : USRDS 2004 Annual Data Report, National Institute of Diabetes and Digestive and Kidney Diseases. Bethesda, MD: The National Institute of Health; 2004. 
9. Xue JL, Ma JZ, Louis TA: Forcast of the number of patients with end stage renal disease in the US to the yr 2010. AM J, Soc Nephrol 2001 Dec; 12 (12); 2753-8.

10. Coresh H, Astor BC, Greene T; Prevalence of Chronic Kidney Disease and decreased kidney function in the adult US population: Third National Health \& Nutrition Examination Survey. Am J. Kidney Dis 2003, Jan ; 41 (1) : 1-12.

11. Jacobson HR ; Chronic renal failure : Pathophysiology. Lancet 1991, Aug 17; 338 (8764) : 419-23.

12. Levey AS, Coresh J, Balk E : National Kidney Foundation practiceguidlines for kidney disease. Ann Intern. Med. 2003, Jul 15; 139 (2): 137-47.

13. Ruggenenti P, Schieppati A, Remmuzzi G : Progression, remission, regression of chronic renal disease. Lancet 2001, May 19; 357

(9268) : 1601-08.

14. St. Peter WL, School Werth AC, Mc Gowan T; Chronic Kidney Disease: Issues and establishing program and clinics for improved patient outcomes. Am J Kidney Dis 2003 May; 41 (5) 903-24.

15. Lewis EJ, Hunsicker LG, Bain RP : The effect of angiotensin- converting enzyme inhibition on Diabetic nephropathy. The collaborative study group. N Engl J Med 1993 Nov 11; 329 (20) : 1456-62.

16. Walser M, Mitch WE, Maroni BJ, Kopple JD : Sould protein intake be restricted in predialysis patients? Kidney Int 1999 Mar; 55 (3) : 771-7.
17. Allon M : Hyperkalemia i end- stage renal disease mechanisms and management. J Am Soc Nephrol 1995 Oct; 6 (4) : 1134-42.

18. Slatopolsky E, Berkoben M, Keber J; Effect of calcitril and non- calcium Vit D analogs on secondary hyperparathyroidism. Kidney Int. Suppl 1992 Oct; 38: 543-3.

19. Uribarri J : Acidosis in chronic renal insufficiency Semin Dial 2000 Jul-Au; 13 (4) : 232-4.

20. Muirhead N, Bargman J, Burgess E, et al: Evidencebased recommendations for the clinical use of recombinant humanerythropoietin. Am J Kidney dis 1995 Aug; 26 (2 Suppl 1) : S 1-24.

21. Mailoux LU: Hypertensi Pathophysiology \& outcomes. Semin Nephrol 2001 Mar; 21 (2) : 14656.

22. Hakim RM, Lazarus JM : Initiation of Dialysis. J Am Soc Nephrol 1995 Novl 6 (5) : 1319-28.

23. Levey AS, Bosch JP, Lewis JB; A more accurate method to estimate glomerula filtration rate from serum creatinine; a new prediction equation. Modification of Diet in Renal Disease( M D R D ) study group, Ann Intern. Med. 1999 Mar 16, 130 (6) : 461-70.

24. Jacobs D, Demott W, et al., Laboratory Test Handbook, $4^{\text {th }}$ ed. Lexi-Comp. Inc. Hudson, Ohio 1996 P-117-18.

25. Kobrin S, Aradhye S. Preventing Progression and complication of renal disease. Hosp. Med. 1997; 33: 11-40. 